\section{A Crítica da Epistemologia na Sociologia do Conhecimento de Karl Mannheim}

Luís de Gusmão

Resumo: O artigo analisa a crítica da epistemologia normativa na obra de Karl Mannheim, sublinhando a sua presença tanto na fase mais filosófica, associada ao elogio do historicismo, como na Sociologia do Conhecimento posterior. Chama a atenção também para a atualidade dessa crítica: ao censurar os epistemólogos do seu tempo por não levarem na devida conta os achados das ciências empíricas particulares, Mannheim antecipa, em décadas, tendências mais recentes da Sociologia do Conhecimento e da reflexão epistemológica.

Palavras-chave: Sociologia do Conhecimento, Epistemologia Normativa, Filosofia da História

\section{Introdução}

$\mathrm{E}$ m Ideologia e Utopia, Mannheim, antecipando em décadas tendências da epistemologia e da Sociologia do Conhecimento mais recentes ${ }^{2}$, vai censurar uma reflexão epistemológica normativa e apriorística que insistia em ignorar o "problema de como os homens realmente pensam" nos contextos concretos da vida cotidiana, problema esse, contudo, iniludível numa investigação empírica acerca do conhecimento humano. Segundo ele, os epistemólogos erravam ao identificar o conhecimento tal como o concebiam - o produto lógicolinguístico de um sujeito epistêmico abstrato, isolado, desvinculado de qualquer situação existencial - como a única forma possível do conhecimento confiável, desqualificando, assim, aqueles modos de pensamento que resultavam da vida social, nasciam das práticas e para as práticas desenvolvidas no âmbito dessa vida.

Mannheim concede aos epistemólogos - uma concessão que soaria inaceitável aos defensores do chamado programa forte de Sociologia do Conhecimento ${ }^{3}$ ser, de fato, possível encontrar um saber no qual buscaríamos em vão as marcas distintivas de um mundo social particular, um saber destituído, nesse sentido, de raízes sociais e ativistas, expressão, na verdade, de um "ponto de vista de
Recebimento:

30.08.2010

Aprovado:

24.02.2011

1. Professor Adjunto III do Departamento de Sociologia da Universidade de Brasília (UnB) Email: gusmao56@ gmail.com

2. Essas tendências apontam no sentido de um abandono crescente do ponto de vista normativo, preocupado com a justificação do conhecimento humano com base em critérios universais de cientificidade, em favor de abordagens empíricas, ancoradas nas contribuições das ciências particulares e voltadas, prioritariamente, para a explicação causal e/ ou funcional desse conhecimento. Nessa perspectiva, a epistemologia assume o status de uma disciplina empírica e já não se distingue essencialmente das ciências empíricas particulares. Essa mudança de assunto, essa preocupação em fazer da epistemologia um empreendimento empírico e não mais normativo, representa uma das principais contribuições da obra de Thomas Kuhn, cujo impacto foi, vale a pena lembrar, enorme no âmbito da Sociologia do Conhecimento mais recente (ver Barnes, 1986). 
O ponto de vista normativo, na sua expressão mais estridente, mais maçante, pode ser encontrado, por sua vez, na obra de Popper e de sua escola, autores nos quais a Teoria da Ciência aparece claramente como uma província da filosofia moral. Para um instrutivo confronto entre esses dois pontos de vista, ver Imre Lakatos e Alan Musgrave: $A$ Crítica e o Desenvolvimento do Conhecimento, São Paulo: Cultrix: Ed. da Universidade de São Paulo.

3. O programa forte de Sociologia do Conhecimento, elaborado por sociólogos da Unidade de Estudos da Ciência da Universidade de Edimburgo, em particular por Barry Barnes e David Bloor, representou uma tentativa de naturalização da epistemologia com base na análise sociológica, tentativa esta que pretendia deixar para trás o ponto de vista normativo e apriorístico da veIha epistemologia. Nessa perspectiva, não apenas os erros mas também os acertos da investigação científica deviam ser explicados sociologicamente. Sendo assim, já não havia lugar para essa velha epistemologia. Numa aberta ruptura com a Sociologia do Conhecimento mais tradicional, exemplarmente nenhum lugar", na formulação tão sugestiva de Thomas Nagel. Tal saber não constituía, portanto, concede Mannheim, uma invencionice filosófica, pura ficção normativa cuja única função seria proporcionar um padrão transcendental com base no qual uma epistemologia normativa e apriorística, cada vez mais distanciada das ciências empíricas particulares, decidia taxativamente acerca daquilo que devia ou não contar como conhecimento racional. Mannheim não vai tão longe assim em sua crítica da reflexão epistemológica! O conhecimento tal como os epistemólogos o concebiam, admite ele, de fato existia. Contudo, prossegue Mannheim, esse conhecimento só podia ser encontrado em campos especiais da investigação científica, nas ciências naturais e exatas, não esgotando, portanto, o universo do conhecimento humano confiável. Cabia incluir também, nesse universo, aquele saber existencialmente condicionado, perspectivista, ligado à ação, do qual os indivíduos (aí se incluindo os epistemólogos!) sempre se valiam quando precisavam tomar decisões práticas nos contextos da vida coletiva. Não havia razão para excluí-lo, não havia razão para estabelecer uma disjunção total, exclusiva, entre tal saber e aquilo que admitíamos como conhecimento confiável. O saber formal, abstrato, desenraizado, cuja expressão mais acabada podia ser encontrada nas ciências naturais e exatas, não constituía, ao contrário do que sugeria a reflexão epistemológica, todo o conhecimento humano possível.

Contra os epistemólogos de seu tempo ${ }^{4}$, mas também, em larga medida, contra a teoria da ideologia em Marx, que insistiam em vincular o erro intelectual, a cegueira ideológica, na linguagem marxista, à influência negativa das situações existenciais no mundo das ideias, Mannheim vai afirmar a possibilidade do conhecimento objetivo existencialmente enraizado. A compreensão dessa possibilidade resultaria, por sua vez, de avanços da investigação social que tinham em Marx o seu ponto de partida. Vejamos isso mais de perto.

\section{Marx e a Sociologia do Conhecimento}

Segundo Mannheim, um conjunto de circunstâncias sociais, políticas e intelectuais, associadas ao advento do mundo moderno, tais como a ascensão das classes médias, a democratização do sistema político e o colapso do monopólio intelectual da Igreja, tão acentuado no mundo medieval, havia tornado cada vez mais visível o fenômeno do condicionamento social das ideias: pontos de vista divergentes, mas com igual pretensão de validade, passavam a ser sustentados pelos distintos grupos sociais, e tais divergências intelectuais, longe de soarem independentes das acirradas lutas econômicas e políticas nas quais esses grupos se envolviam, ali encontravam, na realidade, as suas raízes mais profundas. Em 
outras palavras, no embate das ideias ecoavam diferenças e antagonismos extrateóricos, existenciais.

A teoria marxista da ideologia representava um lúcido e pioneiro reconhecimento desse fenômeno. Com efeito, Marx tinha sublinhado acertadamente as raízes sociais e ativistas de determinadas doutrinas filosóficas, econômicas e políticas de seu tempo, revelando o quanto tais doutrinas, longe de habitarem um platônico (ou popperiano!) mundo das "ideias em si", expressavam, na verdade, pontos de vista particulares de classes sociais particulares.

Assim, por exemplo, em A Ideologia Alemã, obra seminal no desenvolvimento da moderna Sociologia do Conhecimento, Marx vai sugerir, esta é a hipótese central do livro, uma conexão, no mesmo passo causal e funcional ${ }^{5}$, entre as ideias filosóficas de autores como Bruno Bauer e Max Stirner, os jovens hegelianos contra os quais asperamente polemiza, e as condições sociais e políticas da Alemanha nos anos 40 do século XIX: o gosto por abstrações vazias, destituídas de qualquer conteúdo empírico, a inclinação especulativa, a ausência completa de um sentido de realidade, a incapacidade, em suma, de ver as coisas como elas realmente são, tão acentuada na reflexão filosófica dos jovens hegelianos, expressaria, na verdade, a miséria da sociedade alemã dessa época, mais exatamente de sua burguesia: esta, num contraste vivo com sua congênere francesa, protagonista de uma revolução exemplar, não se revelava capaz de promover as mudanças sociais e políticas necessárias à consolidação de seu domínio de classe, pois abria mão, temerosa do avanço das massas, da revolução burguesa, renunciava ao poder político direto, conciliava vergonhosamente com o passado feudal, obstaculizando assim o progresso social.

A Alemanha atrasada, retardatária numa era de Revoluções, assustada com os desafios formidáveis colocados pelo curso da história, produzia, assevera Marx, uma filosofia complacente com o presente, pseudocrítica, escapista. Para os filósofos, a Alemanha se encontrava então às voltas com uma revolução grandiosa, sem precedentes, uma revolução diante da qual as jornadas francesas de 1789 não passavam de brincadeiras de criança. Portanto, sugeriam eles, as coisas corriam muito bem no mundo alemão! Contudo, prossegue Marx, tal revolução não passava, na verdade, de uma fantasia filosófica, pois, longe de envolver, como fora o caso na França, as classes sociais numa luta real, longe de implicar mudanças reais nas relações entre os homens, resumia-se numa disputa estridente entre fraseologias rivais - os conflitos no interior da escola de Hegel, contrapondo jovens a velhos hegelianos -, numa tagarelice filosófica vazia que deixava intocada a sociedade alemã, servindo tão somente para desviar a atenção dos graves e inescapáveis problemas colocados para essa sociedade. representada nos estudos de Merton sobre a ciência, os porta-vozes do programa forte vão se recusar a uma divisão de tarefas com os epistemólogos normativos, divisão na qual caberia aos últimos a explicação do sucesso da investigação científica, concebido aqui como triunfo da razão universal, e aos sociólogos tão somente $o$ inventário dos fatores "externos" que vieram obstaculizar, em circunstâncias particulares, esse triunfo. Com isso, a Sociologia do Conhecimento vai convergir com as ideias de Quine e Kuhn no sentido de conceber a reflexão epistemológica como um empreendimento essencialmente empírico. Para uma crítica desse programa de pesquisas, ver Laudan (1981), e para uma crítica dessa crítica, ver Bloor (1981).

4. Mannheim, nessa crítica, não costuma citar autores e textos particulares, mas parece ter em mente, em algumas passagens, o chamado empirismo lógico. Para uma exposição clássica das teses dessa escola filosófica, ver Ayer (1946).

5. A presença de explicações funcionais em Marx foi lucidamente sublinhada pelo chamado marxismo analítico, de longe a mais 
sensata, a menos obscurantista interpretação da obra marxiana.
Nesse sentido, os filósofos, os ideólogos, como Marx os denomina, traduziam numa linguagem obscura, pedante, no jargão hegeliano, a incapacidade do burguês alemão de encarar a realidade, de responder aos desafios do presente, levando a cabo mudanças sociais e políticas cada dia mais inadiáveis. Os jovens hegelianos, conclui Marx, falam da necessidade de substituírem a "consciência atual" por uma consciência filosófica "crítica", mas, na verdade, são os maiores conservadores, pois "não é lutando contra a fraseologia de um mundo que se luta contra o mundo que realmente existe" (MARX, s/d, p. 17). O significado objetivo do que se passava no mundo intelectual alemão dessa época devia ser buscado, assim, fora desse mundo, devia ser buscado nas condições sociais e políticas concretas da sociedade alemã de então.

Marx, contudo, observa Mannheim, não levara esse lúcido reconhecimento da determinação social do epistêmico às últimas consequências, pois se limitara a pensá-la em termos de uma sociologia do erro. Com efeito, para Marx, as formas de pensamento socialmente condicionadas ou ideológicas, como prefere chamar, constituíam uma falsa consciência, uma imagem distorcida das coisas, objetivamente comprometida com estruturas de dominação econômicas e políticas, não conhecimento confiável acerca do mundo social. É nesses termos que Marx pensa a determinação social das ideias. Assim, soa compreensível o fato de que jamais tenha situado o conhecimento científico, aí se incluindo a sua própria obra - é assim que ele a percebe -, na superestrutura ideológica do mundo social. Com isso, Marx acaba reduzindo a análise sociológica das raízes pré-teóricas, existenciais, do conhecimento humano à denúncia da presença intelectualmente destrutiva dos interesses sociais e políticos na produção desse conhecimento. Do ponto de vista marxista, com efeito, a revelação dessa presença implicava invariavelmente a desqualificação intelectual. Desse modo, Marx permanece ainda muito próximo da reflexão epistemológica tradicional ao associar o erro ao enraizamento sócio-histórico da vida intelectual.

Contudo, o andamento subsequente da investigação sociológica, assegura Mannheim, vai deixar para trás as limitações da teoria marxista da ideologia, com base num duplo passo, a saber: 1) ampliando a hipótese relativa à determinação existencial das ideias, de modo a incluir, nos domínios dessa determinação, o conjunto do conhecimento social, aí se incluindo o marxismo e os desenvolvimentos posteriores da Sociologia do Conhecimento, que adquiria assim uma dimensão autorreflexiva - em Ideologia e Utopia, por exemplo, Mannheim vai estabelecer as circunstâncias sócio-históricas que tornarão possível essa sociologia; 2) dissociando tal determinação da inevitabilidade do erro intelectual e, em decorrência disso, acolhendo a possibilidade do conhecimento objetivo socialmente enraizado.

Nessa perspectiva, a elucidação das raízes sociais e ativistas de um determinado 
ponto de vista já não implicava necessariamente a sua desqualificação intelectual: o saber do qual se valiam os seres humanos nos contextos concretos da vida cotidiana trazia, cabia reconhecer, as marcas desses contextos, mas não soava plausível reduzi-lo, em razão disso, a mistificações ideológicas.

A Sociologia do Conhecimento deixava Marx para trás ao revelar a universalidade desse condicionamento existencial das "interpretações públicas da realidade social" e ao dissociá-lo da cegueira ideológica comprometida com a preservação de estruturas de dominação. A Sociologia do Conhecimento vinha sublinhar a existência de formas de pensamento indissoluvelmente ligadas aos contextos da ação, eficientes e indispensáveis nesses contextos, formas de pensamento essas que já não cabiam no conceito marxiano de ideologia.

\section{Da Filosofia da História à Sociologia do Conhecimento como ciência empírica}

Mas esses avanços teóricos da investigação sociológica não se mostravam compatíveis, alerta Mannheim, com a ideia de conhecimento objetivo da velha epistemologia. Mais ainda: não soavam sequer possíveis à luz dessa ideia! $\mathrm{Na}$ perspectiva dos epistemólogos, a conquista da objetividade implicava a mais completa eliminação das características particulares, específicas, do sujeito epistêmico, aí se incluindo, naturalmente, todas aquelas que resultavam de sua inserção num dado mundo social: no produto lógico-linguístico, admitido como conhecimento objetivo, tais características simplesmente deviam desaparecer! Caso isso não ocorresse, a almejada objetividade estaria seriamente comprometida. Do ponto de vista dos epistemólogos, a ideia de um conhecimento, no mesmo passo, objetivo e existencialmente situado, soava absurda, inaceitável. Portanto, o confronto com a Sociologia do Conhecimento parecia realmente inevitável.

Ora, argumenta Mannheim, como a reflexão epistemológica, longe de ser independente dos progressos realizados no âmbito das ciências empíricas particulares, como sugeria a ambição fundacionista dos epistemólogos, dele dependia, a mencionada incompatibilidade colocava a necessidade iniludível de uma revisão do conceito vigente, tão central na reflexão epistemológica, de objetividade. As descobertas empíricas da Sociologia do Conhecimento não precisavam ser legitimadas por uma epistemologia desenvolvida numa época em que tais descobertas não haviam sido feitas. A relação inversa na realidade se impunha: cabia à epistemologia atualizar-se, ajustar-se às novas evidências empíricas disponíveis, com elas tornar-se compatível. Sendo assim, assevera Mannheim, a Sociologia 
do Conhecimento implicava uma salutar e bem-vinda renovação da reflexão epistemológica (ver Mannheim, 1982, p. 90, 309, 310).

Não seria, talvez, exagerado dizer que a Sociologia do Conhecimento de Mannheim consiste, em larga medida, numa verdadeira cruzada na qual o infiel aparece na figura de uma epistemologia supostamente caduca, prisioneira que é de uma concepção de conhecimento objetivo demasiado restritiva e excludente, fruto da eleição, compreensível mas indébita, de um tipo particular de conhecimento - aquele encontrado apenas nas matemáticas e nas ciências naturais como o ideal exclusivo e supremo de todo o conhecimento confiável. Ao rejeitar tal epistemologia, Mannheim vai reivindicar o direito da investigação social empiricamente orientada de prosseguir no seu caminho sem ser importunada por um despropositado veto filosófico. Com isso, Mannheim se coloca na posição de porta-voz de uma disciplina empírica, a saber, a Sociologia do Conhecimento, cujas descobertas empíricas estariam sendo desautorizadas por uma epistemologia dogmática, aferrada ao passado intelectual, incapaz de aprender com os avanços da investigação científica.

A polêmica de Mannheim com os epistemólogos passa, vale a pena sublinhar, por duas etapas distintas: numa primeira etapa, muito bem representada no ensaio "Gênese e natureza do historicismo", ele vai censurá-los com base numa Filosofia da História (o historicismo) acolhida, nesse momento, em termos que lembram o elogio do marxismo em Sartre: tratava-se da visão de mundo incontornável dos tempos modernos, uma "força intelectual de extraordinário significado" com a qual todos nós teríamos que nos haver, quiséssemos ou não. Na contramão dessa filosofia, à qual devíamos a compreensão da historicidade inescapável do conjunto dos fenômenos sociais, aí se incluindo o mundo das ideias, os epistemólogos, prisioneiros ainda de uma "filosofia estática da razão", não teriam se dado conta da dimensão histórica, dinâmica, mutável, do entendimento humano, não teriam percebido o quanto as categorias mais gerais desse entendimento variavam, tanto na forma como no conteúdo, ao longo da história intelectual, não cabendo, portanto, concebê-las em termos absolutos. Os epistemólogos, legítimos herdeiros da tradição iluminista, insistiam numa concepção sócio-historicamente desenraizada, supratemporal, da racionalidade humana, mas tal concepção, na verdade, resultava ela própria de uma época, e de uma época que ficava para trás.

Nessa etapa, a crítica da epistemologia levada a cabo por Mannheim é completamente tributária da aceitação entusiástica da Filosofia da História, do historicismo (em Mannheim esses termos parecem intercambiáveis), concebido aqui como uma "metafísica dinâmica" sintonizada com a modernidade. Nesse sentido, tal crítica vai consistir num embate filosófico, numa disputa acirrada entre duas filosofias rivais - epistemologia vs historicismo - 
para saber qual delas merecia o status de "ciência fundamental" de todo conhecimento humano. Mannheim, naturalmente, não alimentava qualquer dúvida acerca do desfecho desse embate. É ele quem escreve: "o lugar da epistemologia como ciência fundamental será ocupado pela Filosofia da História como uma metafísica dinâmica" (MANNHEIM, s/d, p. 151). Por outro lado, vale a pena observar, a legitimidade da investigação sociológica parece derivar aqui da sua compatibilidade com as lições dessa Filosofia da História, pois, para Mannheim, nesse momento, "a sociologia é apenas uma daquelas esferas que, dominadas de forma crescente pelo princípio do historicismo, refletem com mais fidelidade nossa nova orientação na vida" (p. 138). Nessa perspectiva, os epistemólogos aparecem como uns insensatos, indivíduos incapazes de entrar em sintonia com essa "nova orientação na vida".

Contudo, em Ideologia e Utopia e nos ensaios reunidos em Sociologia da Cultura, obras posteriores ao mencionado estudo sobre o historicismo (publicado originalmente em 1924), buscaríamos em vão qualquer elogio da Filosofia da História: as referências, quando aparecem, são todas negativas. Assim, por exemplo, discutindo no capítulo I de Sociologia da Cultura a importância vital, para a investigação sociológica, de reunir e sintetizar as contribuições dos estudos sociais especializados, Mannheim alerta para o risco de se relegar tal síntese "às extemporaneidades dos filósofos da história" (MANNHEIM, 1974, p. 8). A rudeza desse alerta, tão contrastante com a atitude apologética presente no ensaio sobre o historicismo, soa compreensível quando lembramos da importância crescente da metodologia empirista na obra de Mannheim: se as sínteses da Filosofia da História soam agora "extemporâneas", inaceitáveis para a moderna investigação social, isso se deve, sobretudo, ao fato de que não pertencem ao "reino da experiência verificável", lugar onde se situa essa investigação, vivendo antes "na atmosfera rarefeita da especulação".

A Filosofia da História aparece agora como uma reflexão especulativa, destituída de qualquer conteúdo empírico, desenvolvimento das "premissas volitivas" de seus autores, invencionice filosófica "cheia de personificações da história como uma força produtiva, um agente catalisador ou um poder inexorável". Os filósofos da história pareciam conceber o movimento histórico sem levar em conta aquilo que efetivamente se movia, sem referências aos contextos sociais concretos, às forças reais que ali atuavam, únicas responsáveis por tal movimento. Os filósofos da história tinham, na verdade, negligenciado a substância da história. Com isso, acabavam reduzindo a sociedade ao cenário passivo do curso preordenado dos acontecimentos históricos (p. 20-21). Sendo assim, cabia à investigação social empiricamente orientada rejeitar, sim, as "extemporaneidades" desses filósofos.

Em Sociologia da Cultura, Mannheim faz um balanço, tão lúcido quanto 
impiedoso, daqueles aspectos metodológicos das obras de Marx e Hegel nos quais ecoava uma filosofia especulativa da história, aspectos esses incompatíveis, alerta ele, com os procedimentos usuais numa ciência empírica genuína. Após observar que esses procedimentos envolviam a comunicabilidade, suposições partilhadas e critérios públicos de evidência, Mannheim conclui:

\begin{abstract}
Se o edifício conceitual de Hegel é uma teologia racional da ordem política e social de seu tempo, o de Marx é um cânone da Revolução (...) mas, nem o diagnóstico de Hegel nem o de Marx são produzidos de modo análogo ao utilizado pelos irmãos Grimm para detectar a família de línguas indoeuropéias, ou por Mendeleiev para chegar à periodicidade dos elementos atômicos. Pelo contrário, as duas sínteses são versões plenamente desenvolvidas dos pontos de vista iniciais dos autores. O caráter insustentável da presente ordem social é uma premissa volitiva do pensamento marxista, assim como a finalidade do Estado de 1830 é um axioma do pensamento hegeliano. (MANNHEIM, 1974, p. 25)
\end{abstract}

Mannheim reconhece, é bem verdade, as contribuições decisivas de Hegel e Marx para a gênese e o desenvolvimento da moderna investigação social. Não se trata, portanto, de rejeitá-los em bloco. Assim, por exemplo, a sugestão hegeliana de que apenas o recurso a categorias mediatas, não redutíveis à observação direta do fenomênico, sempre atomística e fragmentária, possibilitaria uma visão integrada do mundo da cultura, é acolhida por Mannheim como uma contribuição importante e duradoura à metodologia das ciências sociais, algo que, infelizmente, escapava a um empirismo mais estreito (p. 26-41). Marx, por sua vez, teria estabelecido os alicerces, como já vimos, de uma Sociologia do Conhecimento, ao sublinhar as raízes sócio-históricas das doutrinas econômicas e políticas de seu tempo. Contudo, este é o ponto fundamental, tais contribuições soavam aceitáveis na medida, e apenas na medida, em que se revelavam compatíveis com as severas exigências da pesquisa empírica: utilizar categorias mediatas, assevera Mannheim, não significa "abandonar o reino da experiência verificável para entrar na atmosfera rarefeita da especulação, mas antes passar da visão subjetiva e fortuita à análise objetiva" (p. 26). O condicionamento social das ideias, por sua vez, constituía, repete Mannheim à exaustão, um fato muito bem estabelecido no âmbito dos estudos empíricos do mundo social.

O adeus às ilusões da filosofia especulativa da história, resultante, deixem-nos repetir, da aceitação explícita de princípios metodológicos empiristas, é acompanhado, por outro lado, do enquadramento sociológico da investigação histórica. Mannheim continua sublinhando a relevância de uma abordagem histórica do mundo das ideias ou, com mais abrangência, do mundo da cultura; continua afirmando a necessidade de buscarmos as raízes sócio-históricas desse mundo. 
Contudo, tal abordagem agora é explicitamente colocada sob a égide da sociologia como conhecimento do geral. O que procuramos, esclarece ele, "é uma iluminação sociológica da história". Nesse Mannheim, como de resto, no conjunto da moderna teoria social, com a exceção talvez do Weber de alguns textos metodológicos, as descrições do historiador (ou do etnógrafo), não importa o quanto exaustivas e rigorosas possam de fato ser, nunca bastam por si mesmas, nunca são suficientes na busca de uma compreensão científica dos fenômenos sociais, pois tais descrições só ganham sua plena inteligibilidade à luz da sociologia como conhecimento do geral. Assim, cabia falar numa "iluminação sociológica da história". Em Sociologia da Cultura, essa subordinação do conhecimento histórico à teoria sociológica, uma subordinação, diga-se de passagem, talvez indissociável da própria ideia de sociologia, é formulada por Mannheim nos seguintes termos:

A sociologia geral constitui um legítimo quadro de referência: em virtude de seu alcance geral, suas categorias têm precedência sobre as categorias da descrição histórica. Nesse nível, os fenômenos singulares da história são vistos como combinações particulares de tendências supra-históricas, como são observadas ao nível da sociologia geral. (p. 39)

Com essa passagem progressiva de um Mannheim mais filosófico, entusiasta e paladino da Filosofia da História, concebida como "ciência fundamental", para o Mannheim sociólogo empírico da cabeça aos pés de nossas últimas citações, um autor preocupado em fazer avançar uma ciência empírica da cultura, crítico impiedoso dos arroubos especulativos dos filósofos da história, da tutela, neles tão acentuada, de preocupações extracognitivas, morais e políticas (as referidas premissas volitivas) sobre a investigação social; com essa passagem, deixem-nos repetir, vão estar dadas as condições de possibilidade da segunda etapa da crítica da epistemologia acima sumariamente apresentada.

O Mannheim sociólogo empírico já não censura os epistemólogos com base numa visão totalizante, filosófica, supracientífica do curso da história universal (o historicismo); já não recorre, ao combatê-los, a generalidades metafísicas acerca da historicidade última de todas as coisas, da mobilidade eterna e sempre estruturada do mundo dos homens, preferindo antes sublinhar o fosso que se instalara entre a reflexão epistemológica e descobertas empíricas bem estabelecidas no âmbito da moderna investigação social, no caso, aquelas relativas às raízes sociais e ativistas do conhecimento humano.

Segundo Mannheim, tal fosso resultava do apego dos epistemólogos a uma concepção de conhecimento objetivo, que soava, como já vimos, completamente inadequada em face das descobertas empíricas da Sociologia 
6. Para uma interessante discussão sobre as relações entre a epistemologia normativa e o conhecimento substantivo acerca do mundo oferecido pelas ciências empíricas, ver Laudan (1988) e Worrall (1989). Para uma tentativa de conciliar a naturalização da reflexão epistemológica com as tradicionais preocupações normativas dessa reflexão, ver Kitcher (1998) e Goldman (1998). do Conhecimento. Os sociólogos tinham revelado, com base em pesquisas empíricas, o condicionamento existencial de determinadas formas do conhecimento humano, a saber, aquelas de que se valem os indivíduos nos contextos concretos da vida coletiva. Na contramão dessas descobertas, os epistemólogos, porém, insistiam em vincular a conquista da objetividade à produção de um tipo de conhecimento no qual não deveríamos encontrar jamais as marcas de indivíduos (ou coletividades) particulares, situados em mundos particulares, um conhecimento resultante, na verdade, de procedimentos cognitivos genéricos e universais. Com isso, eles acabavam estabelecendo uma oposição absurda entre o conhecimento objetivo, tal como o concebiam, e parcelas consideráveis do conhecimento humano, identificadas agora como um saber inexato, imperfeito, pré-científico (ver Mannheim, 1982, p. 30). Para Mannheim, tal situação colocava a necessidade de uma revisão da velha epistemologia, de modo a torná-la compatível com as novidades científicas em questão. Em Ideologia e Utopia, Mannheim formula essa necessidade nos seguintes termos:

Não conseguiremos atingir uma psicologia e uma teoria do conhecimento adequadas enquanto nossa epistemologia deixar, desde o início, de reconhecer o caráter social do conhecer, e não encarar o pensar individualizado apenas como um momento excepcional. (p. 59)

Caberia aos epistemólogos aprenderem com as ciências empíricas particulares, acompanharem as novidades ali apresentadas, pois só assim ganhariam a necessária flexibilidade e abrangência ${ }^{6}$. Nas palavras de Mannheim:

\begin{abstract}
Somente através de um recurso constante aos procedimentos das ciências empíricas específicas podem os fundamentos epistemológicos tornaremse suficientemente flexíveis e extensos para não somente sancionar as pretensões das formas mais antigas de conhecimento (sua finalidade original), mas igualmente as formas mais recentes. (p. 310)
\end{abstract}

Semelhantes conclusões, todavia, pressupunham, vale a pena sublinhar, a passagem acima mencionada da filosofia especulativa da história à Sociologia do Conhecimento como ciência empírica. Esta última pertencia por inteiro ao "reino da experiência verificável" e, nessa condição, possuía autonomia e precedência em relação a qualquer presumida "ciência fundamental". O erro dos epistemólogos foi exatamente não terem se dado conta desse fato, foi terem reivindicado para a reflexão epistemológica, numa verdadeira inversão da ordem natural das coisas, uma independência em face das ciências empíricas particulares, na verdade, inexistente.

Embora Mannheim não chegue a sustentar abertamente a necessidade da 
eliminação pura e simples da reflexão epistemológica tradicional, não-empírica, normativa e justificacionista em favor de abordagens resolutamente naturalistas (sociológicas ou não), científicas e não filosóficas, do conhecimento humano, sua polêmica com os epistemólogos parece apontar agora, em larga medida, nessa direção: a epistemologia renovada que resultaria, segundo ele, do reconhecimento daquela dimensão existencial e ativista da vida intelectual, tão lucidamente sublinhada, desde Marx, por uma investigação social empiricamente orientada, já não guardaria muita semelhança com a velha epistemologia, uma disciplina filosófica com status quase transcendental, situada, de fato, fora e supostamente acima do mundo das ciências empíricas particulares, autoproclamada guardiã da razão universal. Mannheim vai rejeitar categoricamente a possibilidade e a legitimidade de semelhante disciplina e, nessa rejeição, antecipa em muitas décadas as abordagens naturalistas da epistemologia e da Sociologia do Conhecimento mais recentes.

\section{Sociologia da reflexão epistemológica}

Na cruzada que leva a cabo contra os epistemólogos de seu tempo, Mannheim não se limita a uma afirmação genérica acerca da precedência e autonomia das ciências empíricas particulares em face da reflexão epistemológica. Além disso, fechando o cerco, ele busca o enquadramento sócio-histórico da epistemologia: esta disciplina, longe de situar-se acima de todas as culturas particulares (a suposta condição de possibilidade do conhecimento objetivo), resultaria, na realidade, de um conjunto de circunstâncias sociais e históricas específicas, delas seria uma expressão intelectual. Com isso, Mannheim procura incluir, na lista das provas empíricas disponíveis relativas ao condicionamento social das ideias, o exemplo da própria epistemologia! Contra as ilusões transcendentalistas dos epistemólogos, cabia incluí-la também, ao lado do pensamento social e político, no vasto universo das ideias existencialmente situadas. Vejamos isso mais de perto.

A ideia geral de que a epistemologia, como de resto toda a reflexão filosófica, lança as suas "raízes e fundamento último em solo pré-teórico", atravessa a obra de Mannheim, podendo ser encontrada tanto em sua fase mais filosófica como em seus últimos escritos. Com efeito, já no ensaio sobre o historicismo (1924), localizamos referências às condições sócio-históricas da "doutrina da autonomia da esfera teórica", na qual estaria ancorada a reflexão epistemológica: tal doutrina, esclarece Mannheim, emerge apenas nos tempos modernos, como expressão intelectual de um determinado processo histórico, a saber, o da autonomização progressiva das diferentes esferas da vida social, um fenômeno completamente ausente no mundo feudal que ficava para trás. Nas palavras de 
Mannheim:

7. Em Ideologia e Utopia, Mannheim rejeita a distinção radical, tão cara aos epistemólogos, entre o contexto da descoberta enquanto o conjunto das condições naturais e sociais associadas à gênese de uma determinada ideia, legítimo objeto de investigações empíricas, e o contexto da justificação, espaço das razões lógicas e metodológicas gerais com base nas quais decidimos acerca da aceitabilidade ou não de enunciados ou sistemas de enunciados, sem levar em conta agora quaisquer circunstâncias vinculadas às suas origens, domínio exclusivo da reflexão epistemológica. Segundo Mannheim, tal distinção podia valer para as ciências naturais e exatas, mas não cabia aplicá-la quando se lidava com o conhecimento existencialmente situado. Para uma crítica ainda mais radical dessa distinção, ver Latour (1997).
Como evidência de que os fundamentos da doutrina da autonomia da teoria são pré-teóricos, podemos mencionar de passagem que durante a Idade Média a relação ancilar de subordinação que a filosofia e todas as outras teorias mantinham com a teologia e com a esfera religiosa existente por trás dela, era algo absolutamente acima de qualquer dúvida (...) é no Renascimento que as diferentes esferas da vida começam a se emancipar e atingem a autonomia da ação moral, da criação artística e do pensamento teórico. (p. 149)

Contudo, a sociologia da epistemologia realizada por Mannheim nesse ensaio ainda é demasiado sumária e incipiente, além de completamente tributária de uma filosofia especulativa da história, mais tarde, como já vimos, rejeitada: Mannheim não discute ali, como fará em Ideologia e Utopia, teses epistemológicas específicas, tais como a distinção entre os contextos da descoberta e da justificação7 , limitando-se a investir contra a "filosofia do lluminismo", censurada por encerrar uma "doutrina da supratemporalidade da razão". A Sociologia do Conhecimento ainda aparece ali como uma espécie de subproduto intelectual de uma "metafísica dinâmica" concebida como "ciência fundamental".

Em Ideologia e Utopia, na parte I desse livro, ausente na edição original alemã de 1929, escrita especialmente para a edição inglesa de 1937, Mannheim apresenta, em contrapartida, uma análise sociológica circunstanciada daquilo que teria sido o "solo pré-teórico", existencial, da epistemologia moderna. Segundo ele, essa disciplina filosófica veio responder à necessidade colocada para os modernos, para homens vivendo num mundo onde tudo que era "sólido e estável se esfumava" (Marx), de encontrar um ponto de apoio, um reduto de certezas intelectuais no qual pudessem se ancorar. Com a derrocada da sociedade feudal, acompanhada como fora da contestação bem-sucedida do monopólio intelectual da Igreja e da proliferação de pontos de vista alternativos e rivais, já não se dispunha de uma visão unificada e inabalável do mundo exterior, espelho das coisas como elas realmente são. A crença no ordenamento objetivo desse mundo, no ordenamento independente de qualquer sujeito epistêmico, tão acentuada no pensamento medieval, soçobrava junto com a autoridade inconteste da Igreja, seu maior sustentáculo. O mundo exterior, alvo de interpretações divergentes, já não parecia oferecer um fundamento seguro para o conhecimento humano. Nesse contexto de crise intelectual, fruto de transformações sócio-históricas decisivas, os indivíduos se voltaram, prossegue Mannheim, para o sujeito epistêmico, concebido em termos gerais e abstratos, nele buscando "um ancoradouro para a existência objetiva". Para Mannheim, tanto o racionalismo como o empirismo clássicos apontavam nessa direção. É ele quem escreve: 
Todas essas tentativas [racionalistas e empiristas] pressupõem a consideração mais ou menos explícita de que o sujeito nos é mais imediatamente acessível que o objeto que, como resultado das muitas interpretações divergentes, passou a ser por demais ambíguo. (p. 42)

A epistemologia representava, assim, uma tentativa de solucionar, com base numa análise do sujeito epistêmico, de sua natureza e atividades, o problema dos fundamentos do conhecimento humano, problema esse que soava incontornável para os modernos em razão do colapso da fé incondicional na visão unificada do mundo, de inspiração religiosa até então prevalecente. Nesse sentido, a reflexão epistemológica resultava de uma crise intelectual datada cujas raízes sócio-históricas já estavam bem estabelecidas. Mannheim vai ainda mais longe nesse enquadramento sociológico da epistemologia: não apenas a crise, mas também a solução apresentada trazia as marcas dessa época, lançava as suas "raízes e fundamento último em solo pré-teórico": com efeito, na reflexão epistemológica, com a sua ênfase exclusiva no indivíduo isolado, independente, situado fora de qualquer contexto comunitário, com seu descaso para com o caráter social do conhecimento humano, ecoava, assevera Mannheim, a visão de mundo individualista e subjetivista da sociedade que emergia na Europa das ruínas do mundo feudal (p. 59-60).

Prossigamos. Mannheim vai sublinhar também, nesse enquadramento sóciohistórico da reflexão epistemológica, as conexões entre tal reflexão e as tendências democratizantes associadas às origens do mundo moderno. $O$ ponto de vista epistemológico, centrado nas atividades cognitivas do sujeito epistêmico genérico, aceitando apenas os controles estabelecidos no âmbito dessas atividades, representaria um formidável desafio à autoridade da Igreja como "intérprete oficial do universo": o conhecimento confiável já não deveria ser estabelecido agora com base nos pronunciamentos desse intérprete, mas sim como resultado de procedimentos cognitivos acessíveis, em princípio, a qualquer intelecto. Assim, conclui Mannheim, a reflexão epistemológica vinculava-se, de fato, às inclinações democratizantes da modernidade, ali encontrava o seu lugar.

Em Sociologia da Cultura, no capítulo intitulado "O problema da 'intelligentsia': um estudo do seu papel no passado e no presente", Mannheim segue na mesma direção. Nesse capítulo, com efeito, ele vai destacar as similitudes entre o ponto de vista epistemológico e a "mentalidade democrática" das classes médias em ascensão nos começos do mundo moderno: ambos envolveriam princípios universalistas, niveladores e antiaristocráticos. Os critérios epistemológicos, completamente gerais e abstratos, com base nos quais caberia decidir acerca da aceitabilidade ou não de um dado juízo, deveriam valer para todos os seres humanos, sem exceções. Nessa perspectiva, ninguém, absolutamente ninguém, estava autorizado a dispensar tais controles gerais, e todos, em princípio, 
todos deles poderiam participar: as provas empíricas disponíveis de um juízo factual ou a demonstração rigorosa da necessidade lógica de um juízo analítico podiam ser "objeto de escrutínio por todos os indivíduos". Para os epistemólogos, como para os defensores do ideário político democrático, a publicidade irrestrita soava obrigatória, iniludível.

Nesse sentido, o ponto de vista epistemológico, convergindo aqui com a mentalidade democrática, implicava a mais cabal rejeição da visão de mundo elitista e aristocrática, expressão espiritual de uma sociedade estratificada com base numa rígida distinção entre homens "superiores" e "inferiores", para a qual o conhecimento humano em suas formas mais desenvolvidas, como, de resto, qualquer outro produto cultural socialmente valioso, devia situar-se num "plano superior, inacessível aos homens normais". Os epistemólogos, sintonizados com os novos tempos, apresentavam assim uma teoria geral do conhecimento humano na qual já não havia nenhum lugar para elites epistemologicamente privilegiadas, nem para intérpretes oficiais do Universo, uma teoria na qual ecoava límpida a ideia democrática da igualdade fundamental de todos os seres humanos.

Os epistemólogos vinculavam-se, ainda, à cultura democrática na preferência revelada por abstrações e generalidades, em detrimento da atenção dispensada aos aspectos mais concretos, mais particulares, de seu objeto de análise. Com efeito, o sujeito epistêmico do qual falavam constituía uma entidade altamente abstrata, destituída de qualquer conteúdo particular, situada aparentemente fora e acima da natureza e da cultura. Ora, tal inclinação por abstrações, com o sacrifício dos conteúdos particulares da experiência humana, constituía, na realidade, prossegue Mannheim, um dos traços mais característicos das sociedades democráticas: é que a multiplicidade e a diversidade dos grupos sociais, ali atuando como legítimos protagonistas da vida pública, inviabilizariam as comunicações mais concretas, as mensagens dotadas de conteúdos específicos, acessíveis apenas àqueles indivíduos que dispusessem de "experiências e associações similares". Nesse contexto, o recurso a uma linguagem mais abstrata, mais distanciada das vivências singulares de grupos sociais singulares, representaria a única forma de assegurar uma comunicabilidade mais completa e geral. 0 caráter abstrato da reflexão epistemológica resultaria dessa tendência societária mais ampla, nela lançaria as suas raízes pré-teóricas. Portanto, assegura Mannheim, cabia reconhecer que

A necessidade de abstração e análise não é imposta pelas coisas; sua origem é social; surge a partir das proporções e da estrutura do grupo no interior do qual o conhecimento deve ser partilhado (...) é mais provável que relações abstratas sejam descobertas em sociedades democráticas do que aristocráticas. (p. 156) 
Buscando detalhar mais essa sociologia da epistemologia moderna, Mannheim vai localizar, nas ideias epistemológicas de Kant, relativas ao papel ativo e construtivo do sujeito epistêmico no processo cognitivo, os ecos da experiência social pré-teórica de seu tempo. Nessas ideias, sugere ele, podemos encontrar a expressão filosófica da crescente inclusão social e política de camadas da população até então dependentes e passivas, camadas essas que passavam agora a participar ativamente da vida política dos povos. A concepção kantiana do processo cognitivo como atividade criativa do sujeito epistêmico implicava o abandono de concepções anteriores, nas quais tal sujeito desempenhava um papel puramente passivo e receptivo em face do objeto.

Para Mannheim, essa mudança filosófica acompanhava a mencionada mudança societária mais geral: a epistemologia kantiana traduzia, na linguagem abstrata dos filósofos, a experiência social pré-teórica dos processos democratizantes em curso na Europa. O novo status do sujeito epistêmico correspondia ao novo status social e político dos protagonistas desses processos. Na imagem kantiana do sujeito epistêmico, teríamos o desfecho de um processo cultural mais amplo, cujas origens remontavam à Renascença, de transformações na autoapresentação dos seres humanos nos tempos modernos. Nesse sentido, tal imagem expressava o ponto de vista de indivíduos situados num mundo social particular, numa etapa particular de seu desenvolvimento histórico. Sendo assim, conclui Mannheim, a epistemologia kantiana, como, de resto, o conjunto da moderna reflexão epistemológica, representava, ao contrário do que pareciam supor os epistemólogos, prisioneiros de ilusões transcendentalistas, uma ilustração exemplar da tese sociológica relativa às determinações sócio-históricas do conhecimento humano.

Como já vimos, Mannheim, nesse aspecto sociólogo da cabeça aos pés, subordinava a investigação histórica às verdades abstratas da sociologia geral. Cabia buscar, assevera ele, uma "iluminação sociológica da história". Ora, isso valia igualmente, é supérfluo dizê-lo, para a história das ideias: também, nesse caso, as descrições do historiador não bastavam, devíamos buscar uma "iluminação sociológica" dessas descrições. Nesse sentido, cabia distinguir uma sociologia da epistemologia de uma história das ideias epistemológicas que se limitasse a estabelecer conexões entre tais ideias e contextos sócio-históricos particulares, sem, contudo, desembocar em conclusões de ordem mais geral.

Mannheim leva realmente a sério tal distinção: não se tratava apenas de realizar uma história das ideias atenta ao impacto de circunstâncias históricas particulares num ambiente intelectual particular; não se tratava apenas de demonstrar que uma crise intelectual datada, sócio-historicamente enraizada, resultou numa busca filosófica de fundamentos também datada. Mannheim, como os pais fundadores da moderna teoria social, dos quais é um legítimo e ilustre 
herdeiro, é, antes de tudo, um pensador teórico: embora, como eles, se valha da erudição histórica, dela se beneficie amplamente, busca ultrapassá-la na ambição intelectual, uma ambição intelectual expressa na tentativa de estabelecer, para lá dessa erudição, padrões e relações de dependência mais gerais.

Nesse aspecto, diga-se de passagem, o Mannheim mais filosófico e o Mannheim sociólogo empírico estão muito próximos: ambos subordinam as investigações históricas específicas ao conhecimento do geral, sendo que, para o primeiro, tal conhecimento é identificado com a Filosofia da História enquanto "metafísica dinâmica", ao passo que, para o segundo, ele aparece na figura da moderna teoria social, concebida como ciência empírica genuína.

A Sociologia da epistemologia levada a cabo por Mannheim consiste tão somente numa ilustração particular da hipótese geral, constitutiva da Sociologia do Conhecimento como disciplina teórica, acerca das raízes sociais e ativistas do pensamento humano. Com essa ilustração, Mannheim busca sublinhar a fecundidade e o alcance explicativo de uma história da vida intelectual sociologicamente iluminada: "desvendar o solo pré-teórico" da epistemologia não significava desvendar apenas uma peculiaridade da vida intelectual no Ocidente moderno, mas sim fornecer novas provas empíricas da generalidade e abrangência do fenômeno da determinação social do conhecimento humano. A sociologia da epistemologia vinha demonstrar que, mesmo nas reflexões mais abstratas, aparentemente mais distanciadas dos contextos concretos da ação coletiva, seria possível sim, graças à iluminação sociológica do material histórico, localizar tal determinação. Nesse sentido, a sociologia da epistemologia oferecia uma ilustração histórica particularmente valiosa das verdades gerais da Sociologia do Conhecimento.

\section{Considerações Finais}

Não cabe na extensão limitada deste trabalho, voltado tão somente a uma exposição, a mais fiel possível, das objeções dirigidas por Mannheim aos epistemólogos de seu tempo, um balanço crítico dessas objeções, uma crítica da crítica: isso realmente nos levaria muito longe! Gostaríamos, contudo, nestas considerações finais, de deixar registrado nosso respeito intelectual por esse autor merecidamente identificado por muitos como o último dos grandes clássicos da moderna teoria social. Isso não implica acolhê-lo sem reservas, endossá-lo no conjunto de suas conclusões. Nada mais longe da verdade: se a crítica da epistemologia apriorística e normativa permanece, em larga medida, relevante e atual, o mesmo não pode ser dito do enquadramento sociológico dessa epistemologia levado a cabo por Mannheim. Este, legítimo herdeiro da ambição teórica 
ilimitada de Marx e Durkheim, aposta alto demais na capacidade do conhecimento do geral de tornar plenamente inteligível o conjunto da vida social, e isso o leva a dificuldades de toda ordem: decididamente não é uma tarefa das mais fáceis explicar as formas particulares assumidas pela nossa vida intelectual com base num corpo de conceitos gerais e abstratos ${ }^{8}$.

Seja lá como for, de Mannheim poderíamos dizer, com razão, aquilo que Lênin, já próximo do fim, disse de Rosa Luxemburg: mesmo quando errava, mesmo quando cometia os maiores tropeços, ela não perdia a grandeza, pois uma águia ocasionalmente voando baixo "continua a ser uma águia". A leitura de Mannheim nos deixou plenamente convencidos, pelo menos, de uma coisa: estamos diante de um espírito poderoso, de um grande autor, cuja prosa constitui, ainda hoje, fonte do mais genuíno prazer intelectual. Isso, leitor, convenhamos, decididamente não é pouco!

Abstract: The article analyzes the critique of normative epistemology in the work of Karl Mannheim, stressing its presence both in his more philosophical phase, associated with the praise of historicism, and in his later Sociology of Knowledge. It also calls attention to the relevance of this critique: attacking the epistemologists of his time by not taking into proper account the findings of particular empirical sciences, Mannheim anticipated by decades recent trends in the Sociology of Knowledge and epistemological reflection.

Keywords: Sociology of Knowledge, Normative Epistemology, Philosophy of History

Referências Bibliogáficas

Ayer, Alfred J. (1946) Language, Truth and Logic. New York: Dover Publications.

Barnes, Barry (1986) T.S. Kuhn e as Ciências Sociais. México: Fondo de Cultura Económica.

Bloor, David (1981) "The strengths of the strong programme" in Philosophy of the Social Sciences. n. 11: 199-213.

Goldman, Alvin (1998) "Epistemologia Naturalista e Confiabilismo". in P. C. Abrantes \& Fátima R. Évora (eds.), Cadernos de História e Filosofia da CiênciaNaturalismo Epistemológico. série 3, vol. 8, n.2: 109-145. Campinas, Centro de Lógica, Epistemologia e História da Ciência - Unicamp.
8. Mannheim não dispõe de um corpo de hipóteses universais cujas condições de aplicação tenham sido claramente estabelecidas, mas sim tão somente de um quadro conceitual mais ou menos abstrato, e com base em semelhante ferramenta intelectual simplesmente não é possível oferecer, como sonha esse autor, explicações causais e/ou funcionais situadas além das descrições compreensivas do conhecimento social do tipo conteudístico. Infelizmente, não podemos desenvolver aqui esse ponto de importância, contudo, decisiva num balanço crítico da Sociologia do Conhecimento de Mannheim. 
Kitcher, Philip (1998) "O Retorno dos Naturalistas" in P. C. Abrantes \& F. R. Évora (Eds.), Cadernos de História e Filosofia da Ciência - Naturalismo Epistemológico. série 3, vol. 8, n.2: 27-108. Campinas, Centro de Lógica, Epistemologia e História da Ciência - Unicamp.

Kuhn, Thomas S. (1975) A estrutura das revoluções científicas. São Paulo: Editora Perspectiva S.A.

Lakatos, Imre \& Musgrave, Alan (1979) A crítica e o desenvolvimento do conhecimento. São Paulo: Editora Cultrix/Editora da Universidade de São Paulo.

Latour, Bruno (1997) Ciência em Ação. São Paulo: Editora UNESP.

Laudan, Larry (1981) "The pseudo-science of science?" in Philosophy of the Social Sciences. n. 11: 173-198.

(1989) "If It Ain't Broke, Don't Fix It" in: British Journal for the Philosophy Science, n. 40: 369-375.

Mannhein, Karl (1974) "O Problema de uma Sociologia do Conhecimento" in R. Antonio Bertelli et al (org.) in Sociologia do Conhecimento. Rio de Janeiro: Zahar Ed.

(1976) Ideologia e Utopia. Rio de Janeiro: Editora Zahar.

(1974) Sociologia da Cultura. São Paulo: Editora Perspectiva.

(s/d) Sociologia do Conhecimento. Porto: Editora Rés. Vol. II.

(s/d) "Sociologia" in Maria Alice Foracchi (org.) Coleção Grandes Cientistas Sociais. São Paulo: Editora Ática.

MARX, Karl. (s/d), A Ideologia Alemã. Volume I. Lisboa: Editorial Presença.

(1977) "Manifesto de 1848" in Karl Marx \& Friedrich Engels, Cartas Filosóficas e Outros Escritos. São Paulo: Editora Grijalbo.

(s/d) "Prefácio à Contribuição à Crítica da Economia Política" in Karl Marx \& Friedrich Engels, Textos, Vol. 3. São Paulo: Edições Sociais.

Merton, Robert K. (1970) Sociologia, Teoria e Estrutura. São Paulo: Editora Mestre Jou.

Nagel, Thomas (1998) Una visión de ningún lugar. México: Fondo de Cultura Económica. 
Quine, Willard Van Orman (1991) "A epistemologia naturalizada" in M. M. Carrilho (org.) Epistemologia: posições e críticas. Lisboa: Fundação Calouste Gulbenkian.

Worrall, John (1989) "Fix it and be damned: a reply to Laudan" in British Journal for the Philosophy Science. n. 40: 376-388. 